\title{
Physiological and pharmaceutical effect of fenugreek: a review
}

\author{
Mohsen akbari ${ }^{* 1}$, Hassan Rasouli $^{2}$,Tina Bahdor ${ }^{3}$ \\ ${ }^{I}$ Young Researchers Club, Kermanshah Branch, Islamic Azad University, Kermanshah, Iran, \\ ${ }^{2}$ Research Department of Biotechnology of Drought Resistance, Department of Agriculture College in Razi \\ University, Kermanshah, Iran \\ ${ }^{3}$ Student of Pharmacy in Vivekananda College of Pharmacy, Bangalore, India.
}

\section{SUMMARY}

Plants are used medicinally in different countries and are a source of many potent and powerful drugs. Fenugreek is an medicinal plant that use in disease some therapy. Natural products have been a major source of new drugs [1]. Medicinal plants are used by $80 \%$ of the world population as the only available medicines especially in developing countries [2]. Fenugreek is one of the oldest medicinal plants, originating in India and Northern Africa. An annual plant, fenugreek grows to an average height of two feet [3]. This plant use for blood lipids and sugar decreasing in diabetic and non diabetic peoples and have antioxidant and antibacterial activity. This plant decrease body fats and effective on obesity. This plant use in therapy atherosclerosis [4], rheumatism [5], sugar lowering [6], blood lipids lowering [7], appetizer [8] and contain antioxidant activity [9].

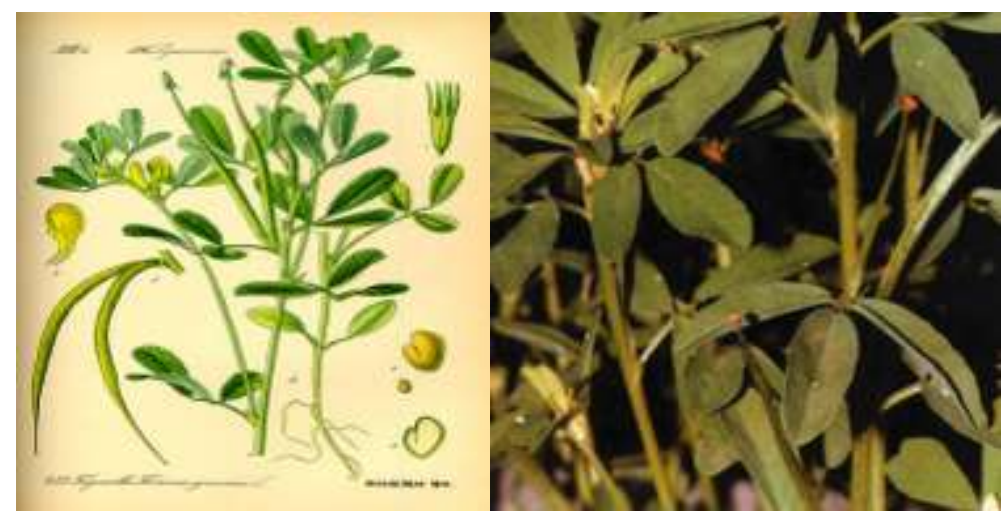

Fig. 1. Images of fenugreek.

\section{Active constituents;}

Fenugreek contains saponins that are transformed in the gastrointestinal tract into sapogenins. Saponins this plant including; Sarsapogenin, Yuccagenin, Smilagenin and, the most important saponin in this plant is Diosgenin [10]. Fenugreek seeds contain 50-percent fiber (30-per-cent soluble fiber and 20-percent insoluble fiber) that can slow the rate of postprandial glucose absorption [3]. Fenugreek seeds, contain oils, alkaloids, amino acids ( lysine, argenine, tryptophan, threonin, valyn and methionin) and musilages that in this plant is most famous galactomannan, too is contain vitamins $\mathrm{A}, \mathrm{C}, \mathrm{D}, \mathrm{B}_{1}$ and , minerals calcium, iron and zinc [10].

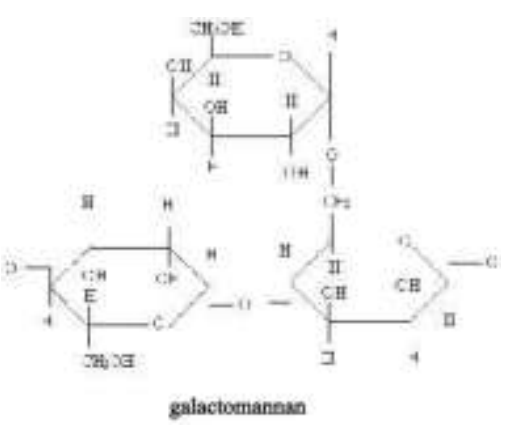

Fig. 2. Galactomannan

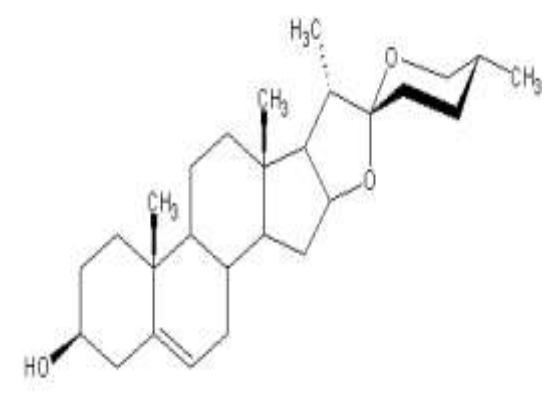

Fig. 3. Diosgenin 


\section{Effects fenugreek on sugar decreasing and diabetes;}

Fenugreek seed powder in the diet reduces blood sugar and urine sugar with concomitant improvement in glucose tolerance and diabetic symptoms in type 2 diabetic patients [15], Too studies $[17,18,19]$, showed hypoglycemic effects of fenugreek seeds type 2 diabetics and [20] conducted a randomized, controlled, crossover trial in 10 patients with type1 diabetes. The hypoglycemic effects of fenugreek have been attributed to several mechanisms. [11] demonstrated in vitro the amino acid 4hydroxyisolcucine in fenugreek seeds increased glucose-induced insulin release in human and rat pancreatic islet cells, It was observed that 4-hydroxyisoleucine extracted from fenugreek seeds has insulin tropic activity [16]. [11] show This amino acid appeared to act only on pancreatic beta cells, since the levels of somatostatin and glucagon were not altered. In human studies, fenugreek reduced the area under the plasma glucose curve and increased the number of insulin receptors, although the mechanism for this effect is unclear. [13] In humans, fenugreek seeds exert hypoglycemic effects by stimulating glucose-dependent insulin secretion from pancreatic beta cells, [12] as well as by inhibiting the activities of alpha-amylase and 50ignali, two intestinal enzymes involved in carbohydrate metabolism. According report [14] The hypoglycemic effect of fenugreek is thought to be largely due to its high content of soluble fiber, which acts to decrease the rate of gastric emptying thereby delaying the absorption of glucose from the small intestine. The cases suggest fenugreek reduced post-prandial hyperglycemia primarily in subjects with diabetes, but less so in subjects without diabetes. This effect might be more pronounced if raw seeds rather than boiled seeds had been used. Fenugreek may aid with insulin secretion, as suggested by animal studies, since typically these patients have little or no endogenous insulin production [3]. Animal tests have proved that galactomannan blocks intestinal absorption of glucose. Water soluble fiber increases the viscosity inside the intestine and then inhibit absorption of glucose.

\section{Effects fenugreek on blood lipids decreasing ;}

According report [21,7], supplementation of these medicinal plants mixture (fenugreek), decreased in serum triglycerides, total cholesterol, LDL-C,VLDL-C in both raw and cooked form but increased in HDL-C with the increase in supplementation of medicinal plants. Studies reported that diabetic state, resulting from an impaired secretion and sensitivity of insulin may be responsible for high triglycerides level in serum than normal individuals, as the insulin stimulated the synthesis of adipose tissue by agency of lipoprotein lipase [22]. Similar decrease in triglycerides and total cholesterol level of the diabetics were observed by feeding fenugreek seeds by various workers [19]. Because fenugreek is contain fiber and fiber have effect of dietary fiber on lipoprotein cholesterol is due to its association with absorption and transport of lipids [23]. Too, according reports, Fenugreek seeds also lower serum triglycerides, total cholesterol (TC), and low-density lipoprotein cholesterol (LDL-C) [24, 25]. These effects may be due to sapogenins, which increase biliary cholesterol excretion, in turn leading to lowered serum cholesterol levels. The lipid-lowering effect of fenugreek might also be attributed to its estrogenic constituent, indirectly increasing thyroid hormone [26]. The quality and quantity of protein in the diets have a direct effect on the levels of cholesterol. Generally plant protein appears to lower cholesterol level [28]. The plant protein in fenugreek is $26 \%$, so it might exert a lipid lowering effect [27]. A study on the extent of degradation of the saponin and/or diosgenin another steroid saponins in the alimentary tract of alloxan diabetic dogs suggested that steroid saponinand sapogenin might have a role in lowering cholesterol [29]. The lipid-lowering potential of diosgenin has been demonstrated by several experimental studies [30]. Diosgenin decreased the elevated cholesterol in serum LDL and HDL fractions in cholesterol-fed rats, and had no effect on serum cholesterol in normo cholesterolemic rats. In addition, diosgenin inhibited cholesterol absorption, and suppressed its uptake in serum and liver, and its accumulation in the liver [31]. Galactomannan influences intestine walls to generate hormones and enzymes and they influence biosynthesis of cholesterol in liver. 


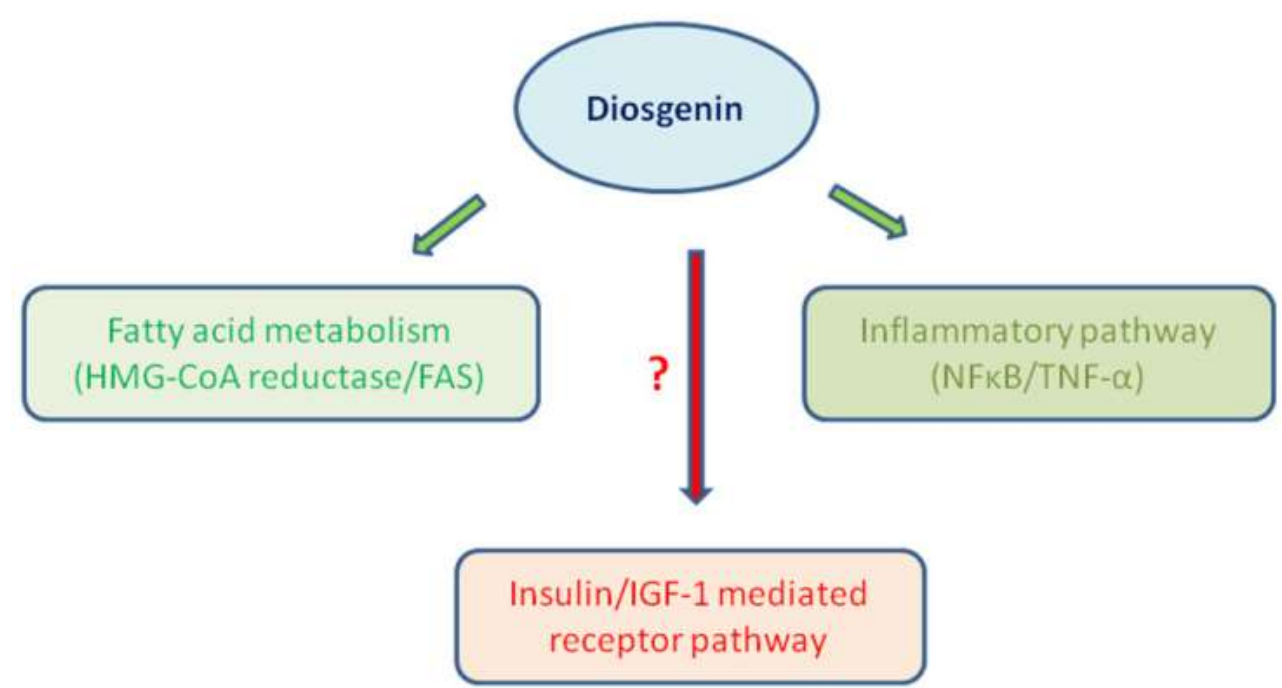

Fig. 4. Schematic representation depicting the molecular mode of action of diosgenin in the control of metabolic pathway. Diosgenin plausibly regulates signaling molecules in fatty acid metabolism and inflammatory pathway. Insulin and IGF-1 mediated 51ignaling pathways may also be regulated by diosgenin.

\section{Antioxidant activity of fenugreek;}

Antioxidants decrease cardiac disease [34], and increase immunity[35], therefore need that supply by body or support of external resources. Spices and herbs possess antioxidant activity and can be applied for preservation of lipid peroxidation in biological systems. Fenugreek (Trigonella foenum-graecum) is an important spice; its dried seeds have wide application in food and beverages as a flavoring additive as well as in medicines[9].The antioxidant property of the plant material is due to the presence of many active phytochemicals including vitamins, flavonoids, terpenoids, carotenoids, cumarins, curcumins, lignin, saponin, plant, sterolandetc[9]. Free radicals are implicated for more than 80 diseases including diabetes mellitus, atherosclerosis, cataract, rheumatism, and other auto immune disease like aging. Etc. in treatment of these diseases antioxidant therapy has gained an utmost importance. Current research is now directed towards finding naturally occurring antioxidant of plant origin. In Indian system of medicine Trigonella foenum graecum is an important medicinal. Antioxidants exert their mode of action by suppressin the formation of reactive oxygen species either by inhibition of enzymes or by chelating trace elements [34]. Antioxidant benefits fenugreek related with exist phenol and saponins, therefore use for liver therapy [35].

\section{Antibacterial activity of fenugreek;}

Screening of medicinal plants for antimicrobial activities is important for finding potential new compounds for therapeutic use. Fenugreek have activity antibacterial, according reports [36,37], this plants kill bacteria. The use of synthetic $\alpha$-glucosidases inhibitors such as acarbose, cause adverse side effects such as abdominal distention due to the excessive inhibition of pancreatic enzymes, resulting in the abnormal bacterial fermentation undigested carbohydrates in the colon. Hence, research on the development and utilization of anti-diabetic plants with mild inhibition of pancreatic enzymes is beneficial [37,38]. The mechanism of inhibition of the glycolytic activity of $\alpha$-amylase may occur through the direct blockage of the active center at several subsites of the enzyme as also suggested for other inhibitors [39]. The $\alpha$-amylase inhibi-tory factors present in the fenugreek extract probably in-teract with the active sites of the enzyme in a substrate specific manner. Fenugreek be effective in inhibiting the growth of Pseudomonas spp., E. coli, Shigella dysentiriae, and Salmonella typhi [40]. 


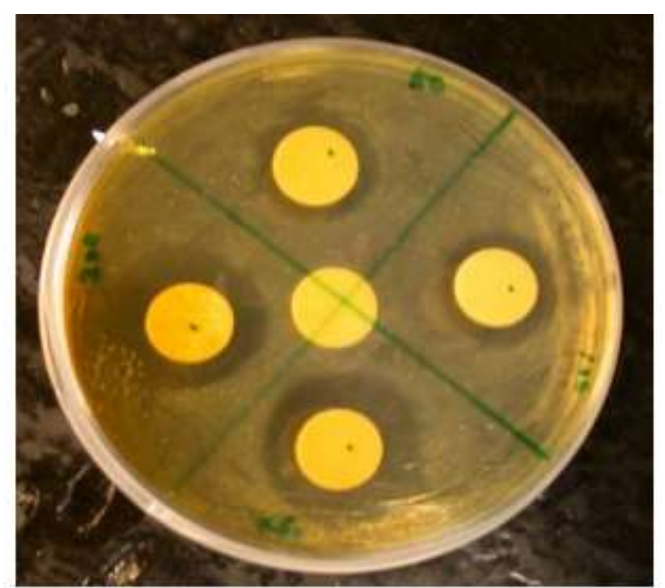

Fig 5. Helicobacter pylori inhibition disk assay. (Center disk represents control; Disk along periphery has increasing concentrations of fenugreek extract 50,100,150,200 $\mu$ Ls starting from top disk in clockwise direction).

\section{Anti-arthritic and vascular protective effects of fenugreek;}

Rheumatoid arthritis is a systemic inflammatory disease associated with generation of oxidative stress that produced vascular dysfunction. Is an autoimmune disorder characterized by synovial proliferation and inflammation, and subsequent destruction and deformity of joints [41]. Not exist much findings related with this activity fenugreek, and not clear mechanism this fenugreek activity, only [42] reported this activity.

\section{Effect of fenugreek on total body and organ weights;}

Obesity is one of the major risk factor for morbidity and mortality. Obesity may be defined as abnormal growth of adipose tissue [43]. Some researchers indicated that fenugreek seed extract supplementation in reducing the body and adipose tissue weight $[44,45]$. The probable mechanism of fenugreek decreasing the total body and adipose tissue weight may be that 1) fenugreek flushes out the carbohydrates from the body before they enter the blood stream resulting in weight loss 2) Fenugreek seeds contain a high proportion (40\%) of soluble fiber. This fiber forms a gelatinous structure (similar to gaur gum) which may have effects on slowing the digestion and absorption of food from the intestine and create a sense of fullness in the abdomen, thus suppresses appetite and promotes weight loss [45]. In conclusion this plant is effective on blood lipids and sugar and on some bacterial strains, antioxidant activity of fenugreek causing protective of organs and inhibition of entrance diseases to body, too decrease body fats and is effective on obesity.

\section{REFERENCE}

[1] P Vuorelaa M, Leinonenb M, Saikkuc P, Tammelaa P, Rauhad JP, Wennberge T, Vuorela H. Natural products in the process of finding new drug candidates. Curr Med Chemistry, 2000; 11(11): 1375-89.

[2] Hashim H, Kamali EL, Mohammed Y. Antibacterial activity and phytochemical screening of ethanolic extracts obtained from selected Sudanese medicinal plants. Curr Res J Biological Science, 2010; 2(2): 143-146.

[3] Ethan B, Grace K, Michael S. Therapeutic Applications of Fenugreek. Altern Med Rev, 2003;8(1):20-27.

[4] Nandini V,S. Devaraj N, Devaraj H . A fibre cocktail of fenugreek, guar gumand wheat bran reduces oxidative modificationof LDL induced by an atherogenic diet in rats.Mole Cell Bio, 2007;294: 145-153.

[5] Vyas Amit S, Patel Nailesh G, Panchal Aashish H, Patel Rameshwar K, Patel Madhabhai M. Anti-Arthritic And Vascular Protective Effects Of Fenugreek, Boswellia Serrata And Acacia Catechu Alone And In Combinations. Pharma Sci Moni, 2010; Vol-1, Issue-2,

[6] Gupta A, Gupta R, Lal B. Effect of Trigonella foenum-graecum (fenugreek) seeds on glycaemic control and insulin resistance in type 2 diabetes mellitus: a double blind placebo controlled study. J Assoc Phys Ind. 2001; 49: $1057-61$.

[7] Xue W, Li X, Zhang J, Liu Y, Wang Zh, and Zhang RJ. Effect of Trigonella foenum-graecum (fenugreek) extract on blood glucose, blood lipid and hemorheological properties in streptozotocin-induced diabetic rats. Asi Pak J Clin Nutr, 2007;16 (Suppl 1):422-426.

[8] Max B. This and That: The essential pharmacology of herbs and spices Trends. Pharma Sci, 1992; 13: 15-20.

[9] Birjees Bukhari S, Bhanger ML, Memon SH. Antioxidative activity of extracts from fenugreek seeds (Trigonella foenumgraecum), Pak J Anna Enviro Chem, 2008; Vol. 9, No. 78-83.

[10] Elnaz H, shamsali R, sayed F, reza DL, jalal Z. Review on fenugreek therapy and phytochemical benefits. Medicinal plants magaz. 2010; Voloum2; 34.

[11] Sauvaire Y, Petit P, Broca C. 4-Hydroxyisoleucine: a novel amino acid potentiator of insulin secretion. Diabetes mag 1998;47:206-210.

[12] Ajabnoor MA, Tilmisany AK. Effect of Trigonella foenum graceum on blood glucose levels in normal and alloxan-diabetic mice. J Ethnopharmacol 1988;22:45-49.

[13] Raghuram TC, Sharma RD, Sivakumar B. Effect of fenugreek seeds on intravenous glucose disposition in non-insulin dependent diabetic patients. Phytother Res1994;8:83-86.

[14] Tim Kr. Herbal support for diabetes management, Adva Nutr Public, 1998; Vol. 6, No. 8. 
[15] Analava M, Debaprasad B. Dose-dependent effects of fenugreek composite in diabetes with dislipidaemia. Internet J Food Safety, 2004; Vol.8, 49-55.

[16] Sauvaire Y, Petit P, Broca C. 4-hydroxy-isoleucine: A novel amino acid potentiator of insulin secretion. Diabetes 1978; 47: 206-210.

[17] Madar Z, Rachel A, Shlomith S, Joseph A. Glucose lowering effect of fenugreek in non-insulin dependent diabetics. Eur J Clin Nutr, 1988; 42: 51-54.

[18] Jain V, Jain P, Sharma S, Kakani R, Hypolipidaemic activity of syndrex, a hydroalcoholic extract of fenugreek seeds Single blind clinical study. Int Med J, 1995; 89:1-41.

[19] Sharma RD, Sarkar A, Hazra DK. Hypolipidaemic effect of fenugreek seeds: a chronic study in non-insulin dependent diabetic patients. Phyto Res. 1996; 10: 332-334.

[20] Sharma RD, Raghuram TC, Rao NS. Effect of fenugreek seeds on blood glucose and serum lipids in type I diabetes. Eur J Clin Nutr1990;44:301-306.

[21] Anita K, Malkit N, Rajbir S. Effect of Supplementation of traditional medicinal plants on Serum Lipid Profile in Non-Insulin Dependent Diabetics. J Hum Ecol, 2007; 22(1): 35-40 .

[22] Matshushita, K., Saito, N. and Ostuji, F.: Factors influencing serum lipid level in patients with diabetesmellitus. J Nutr, 1982; 40: 79-90

[23] Story JA, Kelley MJ. Dietary fibre and lipoproteins. pp 229-36. In: The effect of dietary fibre on lipoprotein cholesterol is due to its association with absorption and transport of lipids Dietary Fiber in HealthDisease. G. V. Vahouny and D. Kritchevsky (Eds.)Plenum Press, New York (1982).

[24] AlHabori M, AlAghbari AM, Al-Mamary M. Effects of fenugreek seeds and its extracts on plasma lipid profile: a study on rabbits. Phytother Res 1998;12:572-575.

[25] AlHabori M, Raman A. Antidiabetic and hypocholesterolaemic effects of fenugreek. Phytother Res 1998; 12:233-242.

[26] Sauvaire Y, Ribes G, Baccou JC, et al. Implication of steroid saponins and sapogenins in the hypocholesterolemic effect of fenugreek. Lipids 1991;26:191-197.

[27] Sharma RD. Effects of fenugreek seeds and leaves on blood glucose and serum insulin responses in human subjects. Nutr Res. 1986; 6: 1353-64.

[28] James H. Atrovastatin reduces remnant lipoproteins and small, dense low-density lipoprteins regardless of the baseline lipid pattern. Prev Cardiol, 2004; 7: 154-60.

[29] Sauvaire Y, Ribes G, Baccou JC, Loubatieres-Mariani MM.Implication of steroid saponins and sapogenins in the hypocholesterolaemic effect of fenugreek. Lipids 1991;26:191-7.

[30] Sauvaire Y, Petit P, Baissac Y, Ribes G. Chemistry and pharmacology of fenugreek. In: Herbs, botanicals and teas. Mazza G and Oomah BD (Eds.) pp 2000; 107-129,

[31] Cayen MN, Dvornik D. Effect of diosgenin on lipid metabolism in rats. J Lipid Res. 1979 ;20: $162-174$.

[32] Subhashini N, Thangathirupathi A, Lavanya A. Antioxidant activity Of trigonella foenum graecum using various In Vitro And Ex Vivo Models . Inter J Pharma Pharma Sciences, 2011; Vol 3, Issue 2.

[33] Noguchi N, Niki E. Phenolic antioxidants: A rationale for design and evaluation of novel antioxidant drug for athero-sclerosis. Free Rad Biol Med. 2000; 28(10):1538-1546.

[34] Young IS, Woodside J. Antioxidants in health and disease. J Clin Pathol. 2001; 54:176-186

[35] Yoo KM, Lee CH, Lee H, Moon B, Lee CY. Relative antioxidant and cytoprotective activities of common herbs. Food Chemistry. 2008; 106:929-936.

[36] Reena Randhir, and Kalidas Shetty and Kalidas Shetty, Improved $\alpha$-amylase and Helicobacter pylori inhibition by fenugreek extracts derived via solid-state bioconversion using Rhizopus oligosporus. Asia Pac J Clin Nutr 2007; 16 (3):382-392

[37] Marles RJ, Farnsworth NR. Antidiabetic plants and their active constituents, Phytomedicine. 1995; 2:137-89

[38] Shani J, Goldschmied A, Joseph B, Ahronson Z, Sulma FG. Hypoglycemic effect of Trigonella foenum graecum and Lupinus termis (leguminosae) seeds and their major alkaloid in alloxan diabetic and normal rats. Archives of International Pharmacodynamics and Therapeutics. 1974; 210:27-36.

[39] McCue P, Shetty K. Inhibitory effects of rosmarinic acid extracts on porcine pancreatic amylase in vitro. Asia Pac J Clin Nutr. 2004; 13:101-06.

[40] BK Dash, S Sultana, N Sultana. Antibacterial Activities of Methanol and Acetone Extracts of Fenugreek (Trigonella foenum) and Coriander (Coriandrum sativum). Life Sciences and Medicine Research, Volume 2011: LSMR-27.

[41] Feldmann M, Brennan FM and Maini RN: Role of cytokines in rheumatoid arthritis. Annu rev immunol 1996; 14:397440.

[42] Vyas Amit S, Patel Nailesh G, Panchal Aashish H, Patel Rameshwar K and Patel Madhabhai M, Anti-Arthritic And Vascular Protective Effects Of Fenugreek, Boswellia Serrata And Acacia Catechu Alone And In Combinations. Pharma Science Monitor, 2010; Vol-1, Issue-2.

[43] Weiser M, Frishman WH, Michaelson MD, Abdeen MA. The pharmacologic approach to the treatment of obesity. J clin Pharmacol 1997; 37:453-73.

[44] Handa T, Yamaguchi K, Sono Y Yazawa K. Effects of fenugreek seed extract in obese mice fed a high-fat diet. Biosci.Biotechbol.Biochem 2005; 69(6):1186-8.46-

[45] Geetha M, Suneel KR, Krupanidhi AM, Muralikrishna K S, Avin A P, Prashanth P. Effect of Fenugreek on Total Body and Organ Weights: A Study on Mice. Pharmacologyonline 3: 747-752 (2011). 